\title{
Evaluation of the influence of uncertain forward models on the EEG source reconstruction problem
}

\author{
Stahlhut, Carsten; Mørup, Morten; Winther, Ole; Hansen, Lars Kai
}

Published in:

Neurolmage

Link to article, DOI:

10.1016/S1053-8119(09)70145-4

Publication date:

2009

Document Version

Early version, also known as pre-print

Link back to DTU Orbit

Citation (APA):

Stahlhut, C., Mørup, M., Winther, O., \& Hansen, L. K. (2009). Evaluation of the influence of uncertain forward models on the EEG source reconstruction problem. In Neurolmage (Vol. 47). Organization for Human Brain Mapping. https://doi.org/10.1016/S1053-8119(09)70145-4

\section{General rights}

Copyright and moral rights for the publications made accessible in the public portal are retained by the authors and/or other copyright owners and it is a condition of accessing publications that users recognise and abide by the legal requirements associated with these rights.

- Users may download and print one copy of any publication from the public portal for the purpose of private study or research.

- You may not further distribute the material or use it for any profit-making activity or commercial gain

- You may freely distribute the URL identifying the publication in the public portal 


\title{
Evaluation of the Influence of uncertain Forward Models on the EEG Source Reconstruction Problem
}

\author{
Carsten Stahlhut, Morten Mørup, Ole Winther, and Lars Kai Hansen \\ Department of Informatics and Mathematical Modelling, Technical University of Denmark, Richard \\ Petersens Plads, 2800 Kgs. Lyngby, Denmark.
}

\section{Introduction}

Electro-encephalography (EEG) holds great promise for functional brain imaging, due to its high temporal resolution, low cost equipment and the possibility of performing the experiments under much more realistic conditions as compared to functional magnetic resonance imaging and positron emission tomography. Todays EEG brain imaging methods operate with the assumption that the forward model is known when the source estimation is performed. Many sources of uncertainty are involved in the formulation of the forward model like tissue segmentation, tissue conductivities, and electrode locations. In this contribution we investigate how forward model uncertainty influences source localization.

\section{Methods}

The analysis were based on 3-spheres models, where a high-resolution reference head model denoted as the 'true forward model' were compared with lower resolution forward models with and without erroneous tissue conductivity values. Conductivities brain:skull:scalp=0.33:0.0041:0.33S $/ \mathrm{m}$ (ratio 1:1/80:1), were used in the true forward model and 1:1/15:1 in an erroneous model. To reveal the influence of the forward fields on the source estimates, we base our analysis on a simple 'stepwise' selection procedure, where a squared error function is used. For simplicity we assume that the true source configuration consists of a single dipole i and we now evaluate the cost estimate of a single dipole solution located at the site $\mathrm{j}$. This allows us to examine how the dipoles are confused in the different areas of the brain when noise is present.

\section{Results}

Due to mismatch between the true and experimental forward model, the reconstruction of the sources is determined by the angles between the i'th forward field associated with the true source and the j'th forward field in the experimental forward model. Figure 1a shows two examples of confusion of the reconstructed sources when the true source is located in left frontal region (Source 1) and left temporal lope (Source 2). The left side on the vertical lines indicates trusted regions where the cost of selecting one of the sources is smaller than the contribution from noise. As confusion measure we use: The positive prediction value $\mathrm{PPV}=\mathrm{TP} /(\mathrm{TP}+\mathrm{FP})$, where TP is true positives (distance $\leq 20 \mathrm{~mm}$ ) and FP is false positives (distance $>20 \mathrm{~mm}$ ) both with angular factors smaller than the effective noise level. Figure 1b-1c show the PPV's for the whole brain with the true and erroneous conductivities, respectively. White areas indicate that no TP or FP has been detected. Generally, small signals from sulci and from cortical regions at a large distance from the sensors are more likely to be confused since the differences in angular factors can be small compared to the effective noise level. Increasing 'white' areas are found in figure $1 \mathrm{c}$ as a result of the poorer signal-to-noise ratio. Confusion is smaller for sources in the parietal region with the erroneous conductivity model, however, the angular factors also increases indicating a poorer representation of the signal.

\section{Conclusion}

This analysis demonstrated that caution is needed when evaluating the source estimates in different brain regions. Moreover, we demonstrated the importance of reliable forward models, which may be used as a motivation for including the forward model uncertainty into the source reconstruction methods. 
Figure 1a: Distance versus $\sin ^{2}(v)$

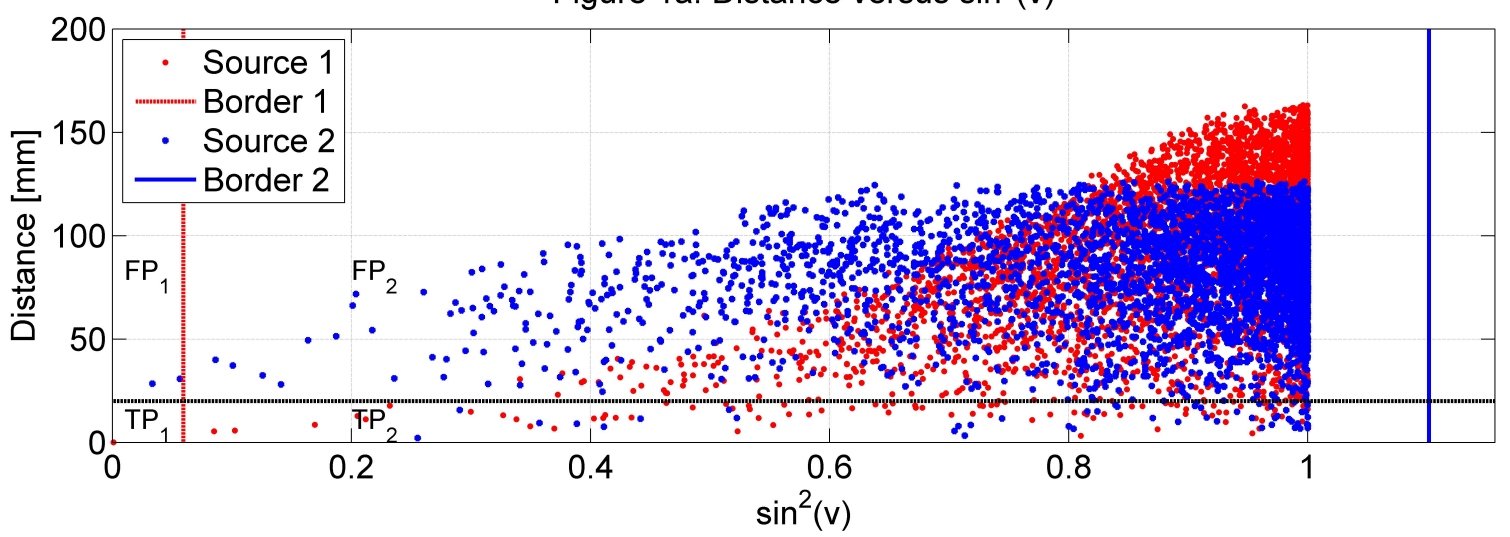

Figure $1 \mathrm{~b}$ : Conductivity ratios $1: 1 / 80: 1$

Figure 1c: Conductivity ratios 1:1/15:1
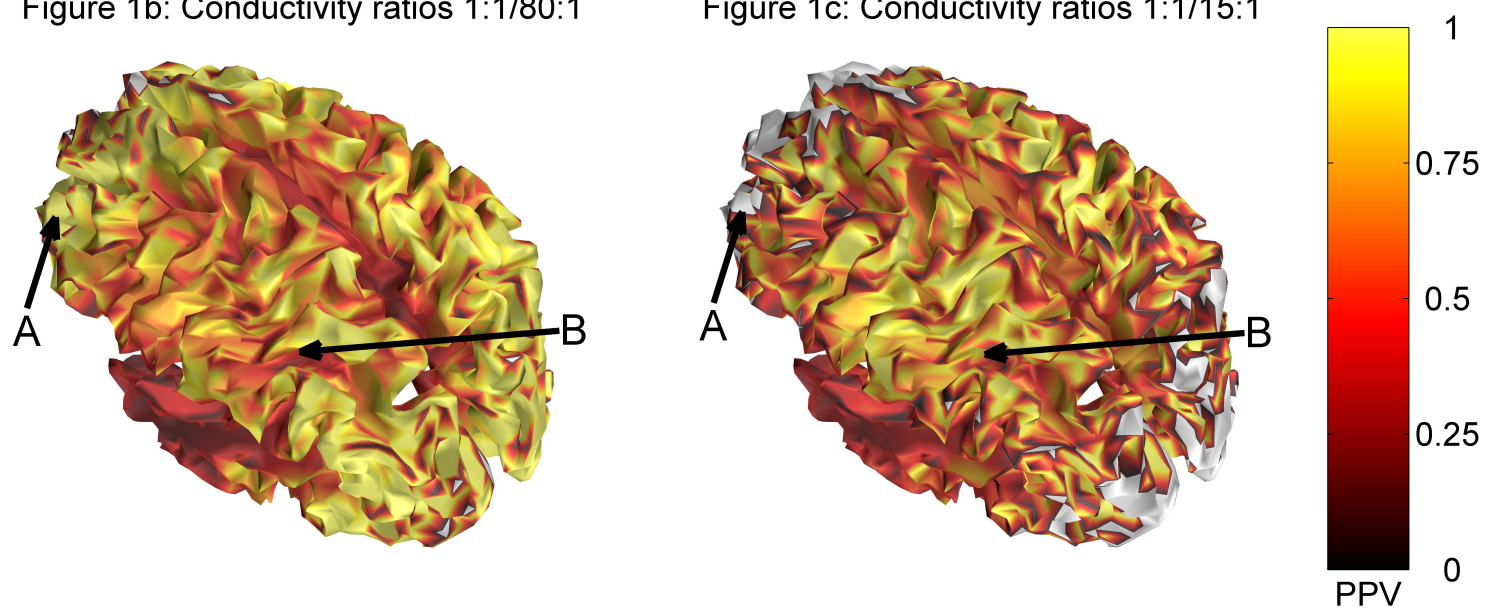

\section{References}

Homma, S., Musha, T., Nakjima, Y., Okamoto, Y., Blom, S., Flink, R., \& Hagbarth, K.E. (1995), 'Conductivity ratios of the scalp-skull-brain head model in estimating equivalent dipole sources in human brain', Neuroscience Research, vol. 22, no. 1, pp. 51-55.

Mosher, J.C., Leahy, R.M., \& Lewis, P.S. (1999), 'EEG and MEG: forward solutions for inverse methods', IEEE Transaction on Biomedical Engineering, vol. 46, no. 3, pp. 245-259.

Oostendorp, T. F., Delbeke, J., \& Stegeman, D. F. (2000), 'The conductivity of the human skull: results of in vivo and in vitro measurements', IEEE Transactions on Biomedical Engineering, vol. 47, no. 11, pp. 1487-1492. 